\title{
Impacts of aspergillosis on sea fan coral demography: modeling a moving target
}

\author{
John F. Bruno, ${ }^{1,4}$ Stephen P. Ellner, ${ }^{2}$ Ivana Vu, ${ }^{1}$ Kino Kim, ${ }^{3}$ and C. Drew Harvell ${ }^{2}$ \\ ${ }^{1}$ Department of Marine Sciences, University of North Carolina, Chapel Hill, North Carolina 27599-3300 USA \\ ${ }^{2}$ Department of Ecology and Evolutionary Biology, Cornell University, Ithaca, New York 14853-2701 USA \\ ${ }^{3}$ Department of Environmental Science, American University, Washington, D.C. 20016-8007 USA
}

Abstract. Little is known about how epizootics in natural populations affect vital rates and population structure, or about the process of recovery after an outbreak subsides. We investigated the effects of aspergillosis, an infectious disease caused by the fungal pathogen Aspergillus sydowii, on the demography of a gorgonian coral, Gorgonia ventalina. Caribbean sea fans were affected by a seven-year epizootic, marked by an initial period in 1994 of high infection prevalence, high mortality rates, and almost complete reproductive failure of infected fans. Post epizootic, in 2005, host populations were relatively healthy, with low disease prevalence.

Using longitudinal data from populations on coral reefs in the Florida Keys (USA) and the Yucatán Peninsula (Mexico), we documented changes in the epidemiology of sea fan aspergillosis over the course of the epizootic. We developed an "integral projection model" that scales disease impacts from individual to population levels using direct estimates of vital rates. Within-colony lesion growth rate and host mortality were higher during the peak of the epizootic. Effects on individuals and populations changed substantially post-epizootic; recruitment increased, mortality of infected adults decreased, and the size dependence of infection was reduced. Elasticity analysis indicated that population growth is more sensitive to changes in the growth and survival of established colonies than to recruitment, due to slow colony growth and the longevity and fecundity of large adults.

Disease prevalence in our monitored populations decreased from $\sim 50 \%$ in 1997 to $<10 \%$ by 2003 and $<1 \%$ in 2007 and was accompanied by very high mortality during the early stages of the epizootic. The population model suggested that host evolution (due to selection for higher disease resistance through differential mortality) could proceed quickly enough to explain the observed changes in prevalence and in the size independence of infection risk. Our model indicates that the time required for population recovery following an outbreak is largely determined by the percentage of healthy tissue lost from the population. However, recovery following an especially severe outbreak (i.e., $80 \%$ or more tissue loss) is much faster if the affected population receives an external supply of recruits from unaffected areas.

Key words: aspergillosis; Aspergillus syndowii; coral disease; Florida Keys, USA; Gorgonia ventalina; host-pathogen interactions; infection rate; integral projection model; population; recruitment; sea fan; Yucatán Peninsula, Mexico.

\section{INTRODUCTION}

Infectious diseases and parasites can strongly affect the population biology of their hosts. Yet, in most cases, little is known about the specific demographic changes caused by infection and the subsequent impacts on host populations. For example, although coral epizootics are a primary cause of coral loss and reef degradation (Aronson et al. 2003), we know very little about how infectious diseases affect the demography of coral populations. It is clear that both infectious and noninfectious coral diseases can increase adult mortality and reduce population density, but we do not know how

Manuscript received 2 July 2009; revised 22 March 2010; accepted 24 March 2010; final version received 17 April 2011. Corresponding Editor: N. J. Gotelli.

${ }^{4}$ E-mail: john_bruno@unc.edu vital demographic properties such as fecundity (but see Petes et al. 2003, Weil et al. 2009) recruitment, and population growth are affected. Likewise, environmental drivers, such as temperature and nutrient concentration, can affect rates of coral disease spread within colonies (Bruno et al. 2003, 2007, Voss and Richardson 2006), but their ultimate effects on host demography are unclear.

This fundamental gap in our understanding of a common and important ecological process has limited our ability to understand and predict the causes, patterns, and timing of disease outbreaks and dynamics. As a result, resource managers and conservation biologists have no baseline for assessing what levels of disease prevalence are a cause for concern, how this is dependent on life history, and, more broadly, how disease severity is related to population recovery time 
and the evolution of resistance. Demographic studies of marine disease are very rare (but see Ford and Figueras 1988, Powell et al. 1996, Linares et al. 2005), and there are no examples of epizootics of colonial animals with their distinctive modular body plan and sometimes great longevity. Clonal and colonial life histories, which lead to demographic phenomena such as strong positive relationships between colony or genotype size and reproductive output (Hughes 1983, Hughes and Connell 1987), can potentially obscure the effects of epizootics on population growth and demography. They can partially decouple common epidemiological parameters such as prevalence (i.e., the proportion of infected individuals in a population) from realized demographic impacts of a disease. For instance, Kim and Harvell (2004) found that the decrease in total colony area caused by sea fan aspergillosis between 1997 and 2003 (about 50\%) was much greater than the decrease in total number of colonies (about 10\%), due to the selective loss of the population's large colonies.

Here we describe a 10-year study of the effects of aspergillosis on sea fan demography. Sea fan aspergillosis is an infectious disease of the gorgonian sea fan Gorgonia ventalina caused by the fungal pathogen Aspergillus sydowii (Smith et al. 1996, Kim and Harvell $2002,2004)$. Infections can cause either partial or wholecolony mortality (Alker et al. 2004, Kim and Harvell 2004). The prevalence and severity of aspergillosis is highly variable among years and populations (Nagelkerken et al. 1997, Bruno et al. 2003, Kim and Harvell 2004, Mullen et al. 2006). Several factors, including population density (Jolles et al. 2002, Mullen et al. 2006), water temperature, and nutrient concentrations (Bruno et al. 2003, Ward et al. 2006, Baker et al. 2007) and between-colony variability in immune response (Ellner et al. 2007) are thought to influence aspergillosis prevalence and severity.

The purpose of this study was to determine how different aspects of disease severity (e.g., infection and recovery rates) affect sea fan demographic processes. For example, we quantified the effects of aspergillosis infection on local recruitment, the growth and survival of colonies, population-level growth, and colony size distribution. Approximately 750 colonies were tagged and monitored at five sites in two regions from 2002 to 2005. We measured a variety of vital demographic rates including colony growth and survival, infection and recovery, and the dynamics of disease lesions. We also measured the effect of aspergillosis on host fecundity, the relationship between adult density and juvenile recruitment, and the population size distribution at additional sites between 1997 and 2006.

We used these data to develop an "integral projection model" (IPM) that scales disease impacts from the individual level up to the population level. The IPM extends the traditional matrix model by recognizing that size is a continuous variable, rather than imposing arbitrary "stage" divisions (Easterling et al. 2000). The model enables us to infer the potential impacts of Aspergillus on sea fan populations, epizootics varying in duration and severity, and the time required for population recovery. We then used elasticity analysis (Caswell 2001, Ellner and Rees 2006) to determine the sensitivity of population-level parameters to changes in specific transition probabilities caused by infections that lead to partial or whole-colony mortality. Finally, we explored whether the rapid decline in disease prevalence could plausibly be due to rapid evolution of resistance in the host, by extending our population model to include selection on resistance resulting from the effects of infection on host survival and reproduction.

\section{Methods}

\section{Sea fan natural history and etiology of aspergillosis}

Sea fans (Gorgonia ventalina and G. flabellum) are a dominant component of shallow Caribbean coral reefs. Like scleractinian corals, gorgonians are primarily autotrophic and are thought to derive most nutrition through carbon fixed by symbiotic, intercellular algae (zooxanthellae) (Falkowski et al. 1984). The dioecious colonies reproduce by broadcast spawning, and larval development is completed in the water column. In general, larval dispersal distances are poorly known for corals. Sea fan (Gorgonia ventalina) microsatellites show a lack of local genetic structure throughout most regions of the Caribbean, suggesting that most adjacent populations are genetically connected (J. Andras, personal communication). Primary mortality sources include predation by the snail Cyphoma gibbosum (Harvell and Fenical 1989), overgrowth by fire coral (Wahle 1980), uprooting by hurricanes (Birkeland 1974), and infection by Aspergillus sydowii and other opportunistic fungi, as well as other undescribed protozoan parasites.

The sea fan aspergillosis outbreak began ca. 1994 in the Caribbean (Nagelkerken et al. 1997), peaked in the late 1990s and has been in decline ever since (Kim and Harvell 2004). Infections can cause either partial or whole colony mortality and, at the height of the outbreak in 1996 and 1997, disease prevalence at some locations exceeded 70\% (Kim and Harvell 2004) (Fig. 1). We estimate that $20-90 \%$ of fans died from infections at some sites in the Florida Keys, Mexico, and the Bahamas. Following this epizootic, the current endemic pattern is for fans to survive many infections and even become uninfected. Recent infection prevalence is below $2 \%$ in the Florida Keys (Fig. 1) and recent assays of purpled colonies in Puerto Rico did not reveal any presence of Aspergillus sydowii (Toledo-Hernandez et al. 2008). In this paper, we refer to the three main stages of the outbreak as "pre-peak," "peak," and "post-peak." The entire epizootic cycle lasted $\sim 7$ years, and the duration of each stage varied.

Signs of aspergillosis include darkly pigmented ("purpled") tissue adjacent to necrotic patches and abnormal growth of the axis (Smith et al. 1996). The 
purple tissue is due to an increase in the proportion of carotenoid-containing purple sclerites (small carbonate skeletal elements) embedded in gorgonian coral tissue (Leverette et al. 2008). Purpling is a generalized response to biotic interactions such as overgrowth by Millepora (Cnidaria, Hydrozoa) and algae, predation by the gastropod predator Cyphoma gibbosum and infection by Aspergillus sydowii (Alker et al. 2004). The purpling is also associated with the development of a melanin layer between the hyphae and healthy tissue and is believed to act as a barrier against the invading pathogen (Mydlarz et al. 2008). This process may result in the formation of thickened areas of tissue and gorgonin, known as "nodules." Purpled areas are more resistant to overgrowth by the fire coral Millepora, which suggests that the response fortifies vulnerable tissue (Alker et al. 2004). This purpling, along with the release of antimicrobial and antioxidant compounds, and a generalized inflammatory reaction, are components of sea fan defense against infection (Ellner et al. 2007, Mydlarz and Harvell 2007).

The origin of pathogenic marine strains of $A$. sydowii is unclear, although recent work indicates a pattern of global panmixia and suggests multiple terrestrial origins (Rypien 2008, Rypien et al. 2008). Because A. sydowii is not known to sporulate underwater (Smith et al. 1996), the local transmission of aspergillosis is hypothesized to occur via hyphal fragments. Work by Jolles et al. (2002) suggested that secondary transmission of the disease during peak years occurred within a range of $2-8 \mathrm{~m}$. It is also possible that the disease can be spread by vectors. Laboratory studies have shown that spores of $A$. sydowii can pass through the gut of the gastropod Cyphoma gibbosum, a predator of sea fans, and remain viable (Rypien and Baker 2009). While some local transmission may occur, recent analysis of long-term aspergillosis monitoring data has shown that aspergillosis incidence and prevalence are independent of host density at most locations. This suggests that disease dynamics are dominated by external pathogen sources (Kim and Harvell 2004).

\section{Demographic monitoring of sea fan populations}

Sea fan populations were monitored on five reefs to quantify a variety of demographic rates. We monitored colonies from January 2002 to July 2005 at five sites: two reefs in the upper Florida Keys, USA (Pickles, $24^{\circ} 59.091^{\prime} \mathrm{N}, 80^{\circ} 24.973^{\prime} \mathrm{W}$; and Carysfort, $25^{\circ} 13.206^{\prime}$ $\mathrm{N}, 80^{\circ} 12.627^{\prime} \mathrm{W}$ ), and on three reefs off the central Yucatán Peninsula, Mexico (Las Redes, 2023.442' N, $87^{\circ} 18.680^{\prime} \mathrm{W}$; Half Moon, $20^{\circ} 24.074^{\prime} \mathrm{N}, 87^{\circ} 18.305^{\prime} \mathrm{W}$; and $\mathrm{Yal} \mathrm{Ku}, 20^{\circ} 24.416^{\prime} \mathrm{N}, 87^{\circ} 18.115^{\prime} \mathrm{W}$ ). All five reefs were shallow forereefs $(6-8 \mathrm{~m}$ depth) dominated by sea fans and other gorgonians after the die-off of Acropora palmata due to the white band epizootic. At least 100 colonies at each site were labeled by attaching an aluminum tag to a nail next to the colony. We labeled new colonies each year to compensate for colony

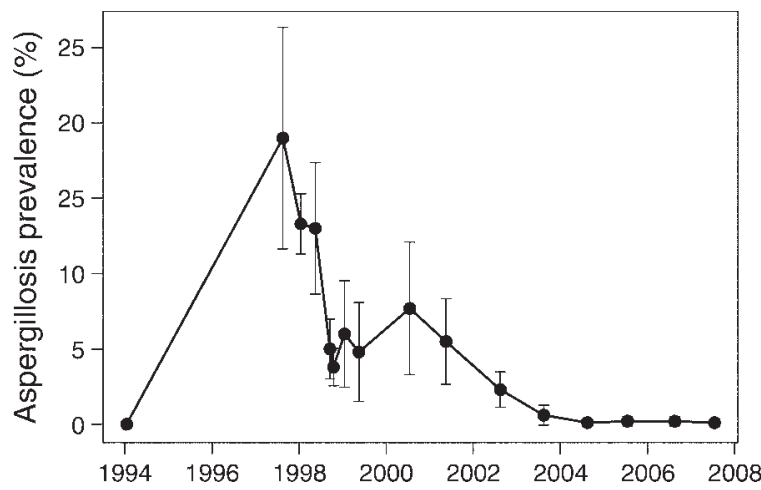

FIG. 1. Prevalence of sea fan aspergillosis in the Florida Keys (USA). Data are from six sites (1997-2004) or five sites (2005-2007). The figure shows means \pm 2 SE. Note that in one instance the Keys-wide survey was carried out over two periods (September 1998 and October 1998) that were separated by Hurricane Georges.

mortality and tag loss. Sites were surveyed up to five times (Table 1).

Each time we surveyed a site we photographed all colonies using a digital underwater camera (Fig. 1; Nikon CoolPix models 990 and 4500). We also recorded which colonies had died since the previous census. Digital images were analyzed using NIH Image J 1.34S software (available online) ${ }^{5}$ to quantify planar colony area and the size of each aspergillosis lesion. We also scored each colony as "healthy" or "infected" based on visual signs of infection recorded in the images. For each lesion we estimated the proportion of area in the following categories: actively growing lesion (indicated by purpling of the tissue), missing tissue (i.e., gaps within an infected area), and colonized (recently dead tissue colonized by algae, invertebrates, and so forth). Image quality was variable, so lesion areas were recorded as "missing data" for cases where the areas of healthy and infected tissue could not be reliably estimated within $15 \%$.

We quantified the rate of sea fan recruitment (the number of new colonies per square meter per year) by recording the number of new recruits each year in 10 permanent $25 \times 2 \mathrm{~m}$ plots at the three sites in Mexico in 2003, 2004, and 2005. Each recruit was labeled (as described above) and its position was recorded so that it would not be counted as a new recruit in the following year's census. We quantified the relationship between adult density and recruitment by counting the number of adult fans and recruits (defined by size cutoffs, as described below in Results) within 30 replicate $1.0-\mathrm{m}^{2}$ quadrats at two Yucatán sites in 2004 (Las Redes and Half Moon).

\section{Transect surveys of sea fan populations}

We also surveyed populations at sites in the Florida Keys (described by Kim and Harvell [2004]) and at

\footnotetext{
${ }^{5}\langle$ http://rsbweb.nih.gov/ij/〉
} 
TABLE 1. Reef sites at which the demographic monitoring of Caribbean sea fan (the gorgonian coral Gorgonia ventalina) populations for aspergillosis infection was performed.

\begin{tabular}{llr}
\hline \hline Location and site & Sampling date & $\begin{array}{c}\text { No. colonies labeled } \\
\text { on sampling date }\end{array}$ \\
\hline Akumal, Mexico & & \\
Half Moon & January 2002 & 82 \\
Half Moon & July 2002 & 76 \\
Half Moon & July 2003 & 95 \\
Half Moon & May 2004 & 103 \\
Half Moon & June 2005 & 75 \\
Yal Ku & January 2002 & 93 \\
Yal Ku & July 2002 & 90 \\
Yal Ku & July 2003 & 126 \\
Yal Ku & May 2004 & 118 \\
Yal Ku & June 2005 & 93 \\
Las Redes & May 2004 & 98 \\
Las Redes & June 2005 & \\
Florida Keys, Florida, USA & 117 \\
Pickles & August 2002 & 26 \\
Pickles & September 2005 & 60 \\
Carysfort & August 2002 & 69 \\
Carysfort & September 2005 & \\
\hline
\end{tabular}

Yucatán sites close to our demographic monitoring sites, between 1997 and 2005 to quantify the frequency distribution of sea fan aspergillosis prevalence and severity. At each site, all living sea fan colonies within three $30 \times 2 \mathrm{~m}$ permanent transects were examined and the maximum height of each colony was measured. Prevalence (the fraction of infected colonies among those surveyed) was determined by examining each colony for signs of infection. Severity was determined by visually estimating the proportion of the colony that displayed purpling or recent tissue necrosis (Kim and Harvell 2002, Bruno et al. 2003). Analyses of the Florida Keys and Mexico transect survey data have been reported elsewhere (Kim and Harvell 2002, 2004, Bruno et al. 2003, Ward et al. 2006). In this paper, data from the transect surveys are used for parameterizing some aspects of the population model representing epizootic peak conditions, and for comparing model predictions with independent field data, taking care that entirely separate data were used for parameterizing and testing. We also used these data to fit allometric models relating colony height and area (Appendix A).

\section{Reproduction}

To quantify the relationship between colony size and reproductive output, we collected two $3 \times 3 \mathrm{~cm}$ tissue samples from each of 42 uninfected colonies of various sizes at Pickles Reef in the Florida Keys in 2002. Colony size was determined as described above (see Transect surveys...). Samples were immediately fixed in $10 \%$ formalin in seawater and subsequently decalcified for $7 \mathrm{~d}$ in an aqueous solution of sodium citrate and formic acid. Measures of reproductive output were obtained at Cornell University (Ithaca, New York, USA) using the histological techniques described in Petes et al. (2003).
On each of two 2-cm axial skeleton strips from each of the two tissue samples, we counted the number of polyps, the number of ova in each polyp, and the size and development stage of each ova. These samples included very few males, so males were excluded from the analysis.

\section{Population-dynamics models}

We used deterministic integral projection models (IPMs; Easterling et al. 2000, Ellner and Rees 2006) to model the effects of aspergillosis on sea fan colonies and populations. The model cross-classifies colonies by two individual-level state variables: disease state (uninfected vs. infected, U vs. I) and the total area of healthy (uninfected) tissue. This model structure reflects the results of our statistical analyses of demographic monitoring data (described below in Results: Demography and infection), because all demographic rates (growth, survival, infection, recovery, fecundity) are modeled statistically as functions of these two individual-level variables. The state of the population is described by two size-distribution functions, one for uninfected and one for infected individuals, respectively, $n_{\mathrm{U}}(x, t)$ and $n_{\mathrm{I}}(x, t)$, with the interpretation that $\int_{a}^{\mathrm{b}} n_{j}(x, t) d x$ is the number of colonies in disease state $j \in\{\mathrm{U}, \mathrm{I}\}$ with size $x$ between $a$ and $b$, at the census time in year $t$. The model structure is then

$$
\begin{aligned}
n_{\mathrm{U}}(y, t+1)= & \int P_{\mathrm{UU}}(y, x) n_{\mathrm{U}}(x, t) d x \\
& +\int P_{\mathrm{UI}}(y, x) n_{\mathrm{I}}(x, t) d x+R \varphi_{0}(y) \\
n_{\mathrm{I}}(y, t+1)= & \int P_{\mathrm{IU}}(y, x) n_{\mathrm{U}}(x, t) d x \\
& +\int P_{\mathrm{II}}(y, x) n_{\mathrm{I}}(x, t) d x
\end{aligned}
$$

where $P_{i j}$ is the projection kernel for colonies in diseasestate $j$ "now" and disease-state $i$ "next year," $R$ is the recruitment rate, and $\varphi_{0}$ is the probability density function for initial size of new recruits. Integrals with respect to $x$ having unspecified limits, such as those in Eq. 1, run from 0 to a finite value larger than the maximum observed value of $x$ in the population being modeled.

The $P$ 's incorporate the rates of mortality, infection, and recovery as well as interannual transitions in size. For parameterizing the model it is useful to separately model the size and state transitions, by writing

$$
P_{j i}(y, x)=s_{j i}(x) g_{j i}(y \mid x)
$$

where $s_{j i}(x)$ is the size-dependent probability that a colony in disease state $i$ at the current census is in disease-state $j$ at the next census, and $g_{j i}(y \mid x)$ is the conditional size distribution for such colonies at the next census. 
The cube root of the area of healthy tissue was used as the measure of colony size $x$, because this transformation was optimal for modeling the growth dynamics of uninfected colonies (the category for which we have the most data), in the following sense. In the IPM framework, growth is modeled through regression analysis of future size as a function of current size and possibly covariates. The relationship between tissue area in year $t+1$ vs. tissue area in year $t$ for uninfected colonies is approximately linear, but with markedly higher residual variance at larger sizes. To avoid modeling variance heterogeneity we sought a variable transformation that would stabilize the variance, within the Box-Cox family of power transformations, using maximum likelihood assuming Gaussian residuals and also a robust estimation method (Seber and Wild 1989: section 2.8). The maximum-likelihood estimate was 0.30 \pm 0.05 (95\% profile-likelihood confidence interval), and the robust estimate was 0.33 - effectively the cube root of tissue area. A normal quantile-quantile plot of residuals from the linear regression with the maximumlikelihood estimate indicated some departures from normality in the tail, so we used the robust estimate.

\section{Statistical analyses}

Statistical analyses were performed in R ( R Development Core Team 2007) version 2.3 or higher, as were all calculations for the population model. Linear or generalized linear demographic models reported below (e.g., logistic regression) were always tested against nonlinear models, both parametric (addition of quadratic terms) and nonparametric spline regressions using the mgcv package (Wood 2008). However, in no case did these offer a statistically significant improvement over a linear model based on our measure of colony size, cuberoot transformed total healthy-tissue area. Linear mixed-effects models were fitted using the lme function in the nlme package (Pinheiro et al. 2007). The potential error of colony area determinations by digital image analysis is very small relative to the range of colony area in the population, so our statistical analyses assume that colony size is measured without error.

\section{Results: Demography and INFECTION}

\section{Reproduction}

Reproductive status of the gorgonian sea fan Gorgonia ventalina was strongly correlated with colony size. The proportion of reproductive colonies varies significantly across size classes $\left(\chi^{2}=13.25, n=42\right.$ colonies; Monte Carlo $P<0.01$ based on $10^{5}$ runs), but does not differ significantly among the three largest size classes (height $25-35 \mathrm{~cm}, 35-45 \mathrm{~cm}, 45-55 \mathrm{~cm}: \chi^{2}=2.96, n=25$ colonies; Monte Carlo $P=0.28$ based on $10^{5}$ runs), or between the two smallest size classes $(5-15 \mathrm{~cm}, 15-25$ $\mathrm{cm}$ ) because only one colony in those size classes was reproductive. Among reproductive colonies, there was no significant relationship between colony size class and the number of ova per unit area $(P=0.89,14$ colonies, one-way analysis of variance with ova totals logtransformed to achieve an approximately Gaussian distribution), or mean ova size $(P=0.65,477$ ova on 14 colonies, fitting a linear mixed-effects model with size class as a fixed effect, colony as a random effect, and ova sizes as the response variable, log-transformed to give approximately normal and homoscedastic residuals). All individuals having ova in the later stages (3 and 4) occurred in the two largest size classes, but this trend was not statistically significant $\left(\chi^{2}=2.3\right.$; Monte Carlo onesided $P=0.23$ based on $10^{5}$ replicates). Thus, there is no evidence in our data of size-dependence in the reproductive output per unit area of reproductive colonies.

\section{Survival and recovery of infected colonies}

An infected colony can be in three possible states at the subsequent census: (1) still infected, (2) recovered (i.e., no longer infected), or (3) dead. Considering these fates separately, there is strong evidence that fans with more healthy tissue have far lower mortality (logistic regression, $P<0.05$ ), and weaker evidence that larger fans are both more likely to remain infected after one year and more likely to recover after one year (estimated logistic regression coefficients are both positive but not significantly nonzero at the $5 \%$ level). However the latter two trends would both occur as automatic consequences of larger fans having a lower death rate. We therefore decomposed the fate functions in Eq. 2 as

$$
s_{j \mathrm{I}}(x)=\left(1-m_{\mathrm{I}}(x)\right) \tau_{j \mathrm{I}}(x)
$$

where $m_{\mathrm{I}}$ is the size-dependent mortality of infected colonies, and $\tau_{j \mathrm{I}}$ is the size-dependent probability of a currently infected fan moving to disease state $j \in\{\mathrm{U}, \mathrm{I}\}$ conditional on survival to the next census.

Infected colonies with less healthy tissue have higher mortality (Fig. 2A, $P<0.05$ for logistic regression of mortality risk on cube-root-transformed total healthytissue area). Because of the small number of deaths we did not test for site or year effects. The fraction of healthy tissue was less successful as a predictor of mortality, and ranged from $10 \%$ to $96 \%$ of total area in the four observed deaths of infected colonies. The data (Fig. 2B) suggest visually that colonies with more healthy tissue are more likely to recover from infection, but this effect is not statistically significant $(P=0.74)$ and the size-independent model also has lower AIC $(\mathrm{AIC}=1.89)$. Effects of site and year on the probability of recovery were not statistically significant $(P>0.2)$.

\section{Survival and infection of uninfected colonies}

Mortality is much lower in uninfected fans and also size dependent (Fig. 2C; $P<0.01$ for logistic regression of mortality risk on size). Effects of year and site on mortality were not statistically significant $(P>0.5$ for addition of either to a general linear model [GLM] with size as predictor). The annual mortality rate of recruits was $33 \%$ (11 out of 33 tagged recruits whose subsequent 

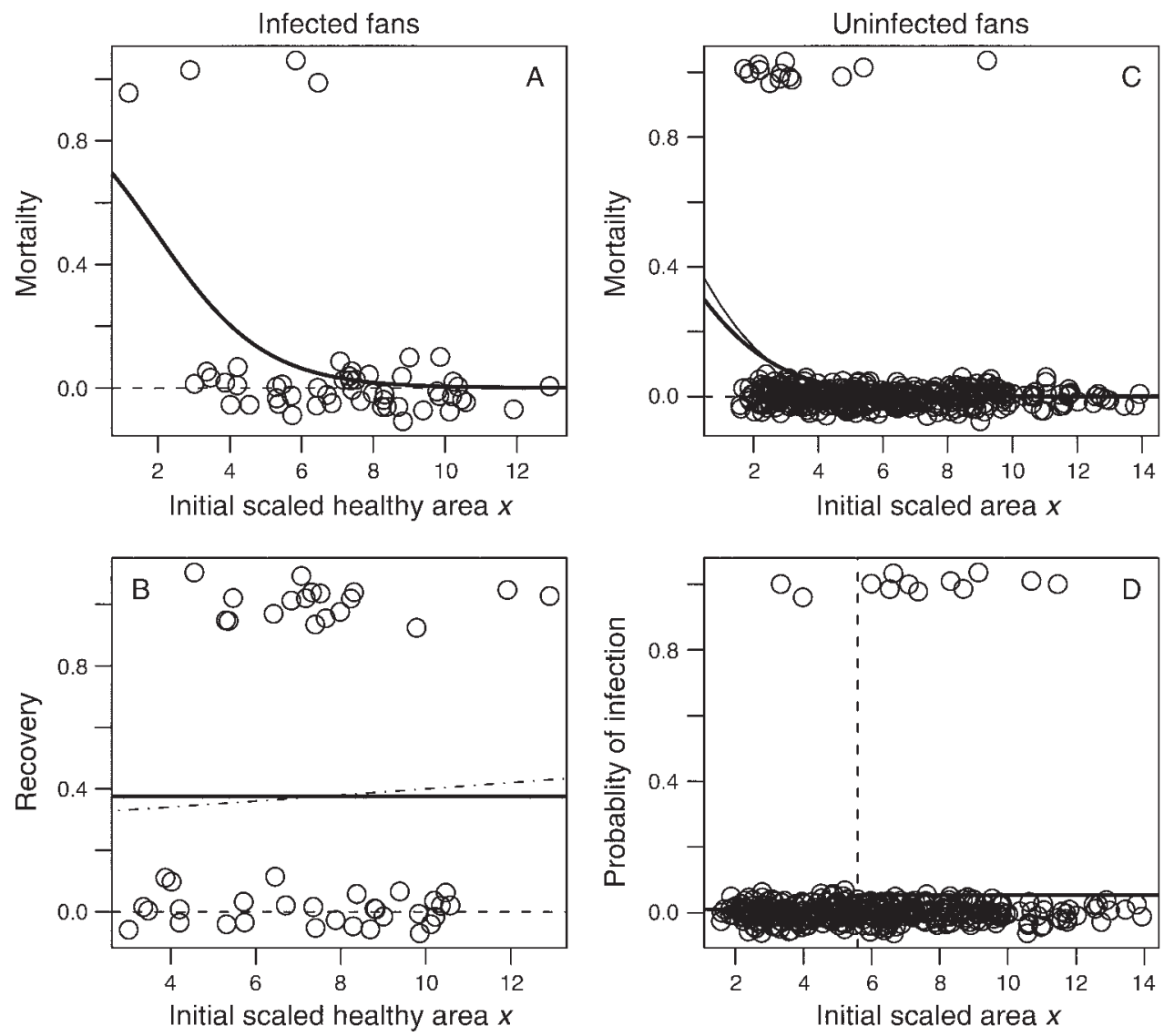

FIG. 2. Models for demographic transition rates as a function of size and disease state, based on the demographic monitoring data (Yucatán Peninsula, Mexico, 2002 and later). The measure of size is $x=$ (initial healthy area) ${ }^{1 / 3}$. Response variables are 0 or 1 , jittered for plotting. (A) Mortality of currently infected colonies (1, died; 0 , survived). The solid curve is the fitted logistic regression model $m_{\mathrm{I}}(x)$, where I indicates the "infected" state variable (see Results.... Survival and recovery of infected...). (B) Probability of recovery for currently infected fans (1, recovered; 0 , remained infected). The solid line shows the size-independent recovery probability assumed in our population model; the dot-and-dashed line is the fitted size-dependent logistic regression model. (C) Mortality of currently uninfected colonies (state variable $\mathrm{U}$ ). The thicker solid curve is the fitted logistic regression model $m_{\mathrm{U}}(x)$; the lighter solid curve is the fitted nonlinear (spline) regression model. (D) Probability of becoming infected for currently uninfected fans (1, became infected; 0, remained uninfected). The step-function solid curve is the piecewise constant size-dependent infection risk assumed in our population model; the dashed vertical line indicates the breakpoint between low and high infection risk, corresponding to the size at first reproduction.

fate could be determined) whereas the predicted mortality rate of new recruits, based on the estimated recruit size distribution, was $22 \%$.

Infection risk also appeared size dependent (Fig. 2D), in that only 2 out of 12 new infections occurred in the smaller half of the colony size distribution; a model with size-dependent infection risk (a step-function increase at area $=175 \mathrm{~cm}^{2}$ ) was significantly better than a model with size-independent infection risk $(P=0.011)$. Effects of year and site on infection risk were not statistically significant $(P>0.3$ for addition of these variables to a GLM with size as a predictor).

\section{Colony growth rates}

Interannual changes in size, i.e., colony growth and shrinkage, were dependent on initial colony size and disease state (Fig. 3). Initially infected fans clearly grow more slowly and also risk extensive healthy-tissue loss (see the three circled "outliers" in Fig. 3), so initially infected colonies were considered separately from initially uninfected colonies.

The size of initially uninfected fans at the subsequent census depends on their initial size $(P<0.001$ in both cases), but not on whether or not they become infected prior to the next census $\left(F_{2,365}=0.267, P=0.76\right.$ for addition of final disease state to a linear model with size as predictor). There were statistically significant effects of site and year, but together (including both main effects and interactions in a linear model) these explained $<0.5 \%$ of the variance in final colony size, so variability among sites and years is negligible for forecasting colony-size dynamics.

The growth patterns of initially infected colonies are quite different. With the three "outliers" in Fig. 3 omitted, 


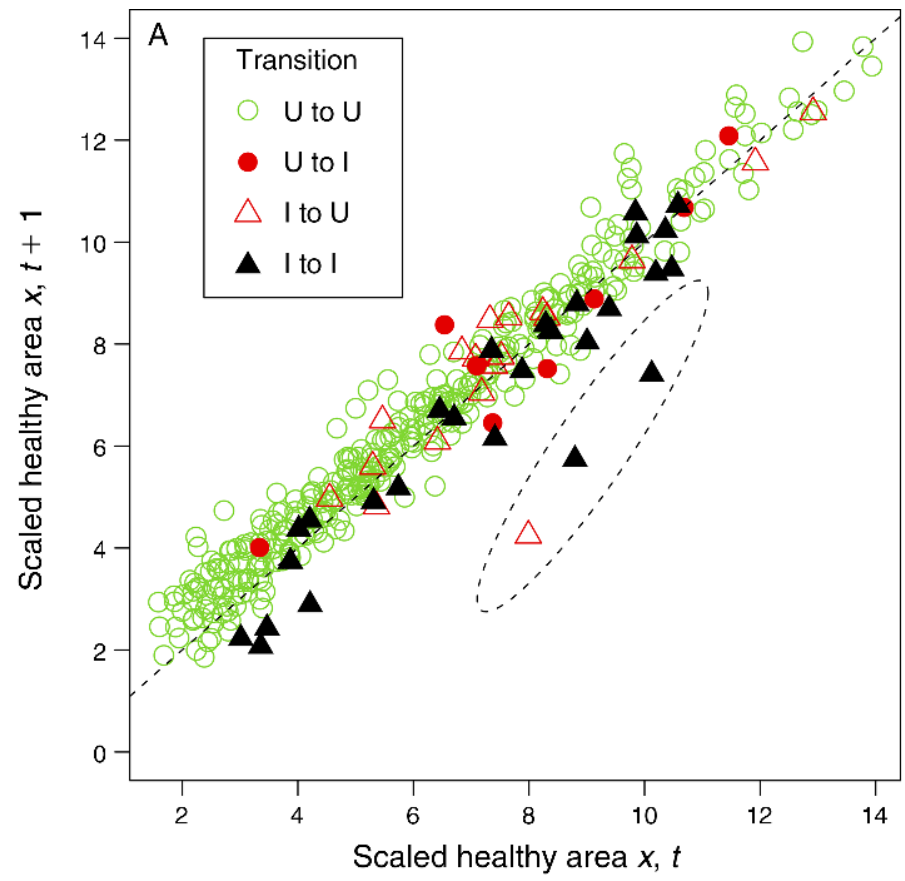

B) 23 July 2002

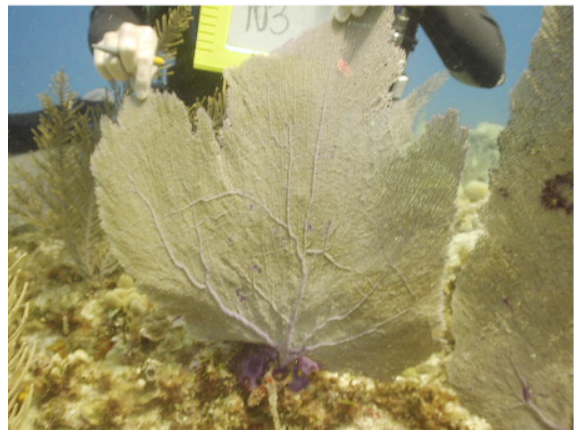

C) 11 June 2003

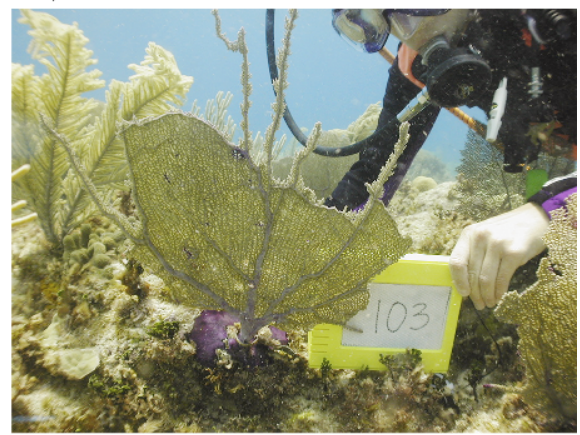

FIG. 3. Transitions between uninfected (U) and infected (I) colony states. (A) Interannual changes in size $x$, classified by initial and final disease state, in the demographic monitoring data (Yucatán Peninsula, 2002 and later). Healthy area was measured in square centimeters and cube-root transformed. Circles indicate colonies that were uninfected at the initial census, and triangles indicate colonies that were infected at the initial census. Open symbols indicate colonies that were uninfected at the final census, and solid symbols indicate colonies that were infected at the final census. The dashed line is the 1:1 line (initial size = final size), and the dashed oval encloses three "outliers" with severe amounts of healthy-tissue loss. (B, C) Photographic example of sea fan size and state transition, from (B) $\mathrm{U}\left(t_{0}\right)$ to (C) I $\left(t_{1}\right)$ and subsequent colony shrinkage between two annual censuses (i.e., one-year transition). Colony 103 became infected and lost $\sim 60 \%$ of its living tissue. Photo credits: J. Bruno.

there is no evidence that growth is affected by initial size, but it is affected by final disease state (specifically, in a linear model with final transformed healthy area $x$ as the response, and initial $x$ and final disease state as predictors, the estimated slope of final size vs. initial size is 1.004 , and the effect of final disease state was highly significant, $P<$ 0.01 ; interaction between initial $x$ and disease state was not significant). On average, initially infected fans that showed no signs of infection the following year grew (change in size $x=0.20 \pm 0.11$ [mean $\pm \mathrm{SE}$ ], $n=18$ fans), while those that remained infected shrank on average (mean change in size $x$ $=-0.12 \pm 0.09, n=35$ fans).

\section{Size dynamics of infections}

Fig. 4 summarizes the observed changes in size of individual lesions ("lesion size" refers to the total tissue area classified as either actively growing lesion, colonized or recently lost due to infection). There is a general tendency for lesions to grow from year to year, on average, with smaller lesions growing faster than larger ones (Fig. 4C). However, there is also an enormous amount of variability in year-to-year lesion size changes: over the range of the data, there is a $25-$ fold to 40 -fold range of variation between the upper and 
lower limits of the $90 \%$ prediction interval for lesion size the following year. This high variability may explain why colonies' total lesion area did not emerge as a good predictor of survival or growth in our statistical analyses. There is less apparent variability in the lesion size changes across a three-year interval in the Florida Keys data (Fig. 4D). However colonies that survived for three years while remaining infected may be a distinctive subset of the population - those able to keep infections in check but unable to completely purge themselves of infection.

\section{Population Model: Development}

\section{Reproduction}

Based on Results: demography and infection: Reproduction (above), the population model assumes that colonies $<20 \mathrm{~cm}$ in height are nonreproductive, while those $>20 \mathrm{~cm}$ and uninfected have reproductive output proportional to their total area. Infected colonies of any size have near-zero reproductive output (Petes et al. 2003). The total recruit production by a population is therefore proportional to the total surface area of uninfected $20 \mathrm{~cm}$ or taller colonies, so the recruitment rate $R$ in Eq. 1 is given by

$$
R=b \int_{x>20} x^{3} n_{\mathrm{U}}(x, t) d x
$$

for some constant $b$. To estimate $b$, we used Eq. 4 with $n_{\mathrm{U}}$ a kernel density estimate of the height distribution based on pooled data from all Yucatán transect surveys in 2004, scaled so that the total abundance of $5 \mathrm{~cm}$ or taller colonies matched the estimated average density in Yucatán sea fan populations (1.1 sea fans $/ \mathrm{m}^{2}$ ). We then solved for the value of $b$ such that Eq. 4 equals the estimated recruitment rate of 0.19 sea fans $/ \mathrm{m}^{2}$, obtaining $b=2 \times 10^{4}$. With this value of $b$, the population state function $n$ is interpreted as describing the number of colonies per square meter in suitable habitat, and the recruitment rate $R$ is the number of new recruits at time $t$ +1 per square meter in suitable habitat.

Equation 4 models a population that supplies its own recruits, i.e., it represents a "global" population of sufficient spatial extent that negligibly few recruits enter from outside. To model a "local" population, where most recruits were produced by parents elsewhere, we instead set $R$ to a constant 0.19 sea fans $/ \mathrm{m}^{2}$, independent of the local population size or structure. Because we found no evidence that recruitment was limited by competition between conspecific colonies, recruitment rates in our models are not affected by population density, although such effects would be expected if populations reach sufficiently high density. However, our population model for the initial disease outbreak incorporates the trend of increased recruitment observed during the study period (Kim and Harvell 2004); see Appendix $\mathrm{C}$ for specifics.

\section{Survival}

The model uses the fitted relationships between size and mortality risk in Fig. 2A, C, logit $m_{\mathrm{I}}(x)=1.3-$ $0.67 x$, logit $m_{\mathrm{U}}(x)=-0.55-0.62 x$. There was equivocal evidence for nonlinear alternatives to the linear logistic regression for uninfected colonies $(P=0.135$ for addition of a quadratic term, $P=0.06$ for a smoothing spline), but the linear and nonlinear models predict nearly identical mortality risks across the observed size range, so we used the linear model.

\section{Infection and recovery}

The size-dependence of infection in the demographic monitoring data (Fig. 2D) corresponds with independent field-survey data indicating that colonies $<20 \mathrm{~cm}$ in height have much lower disease severity and prevalence than larger colonies (Kim and Harvell 2002). This size also corresponds roughly to the size at which reproduction begins, which we speculate might reflect a trade-off between reproduction and defense against infection. To model the size dependence of infection risk we therefore used a step function with the break at $x=5.6$ (corresponding to area $=175 \mathrm{~cm}^{2}$, height $=17.5 \mathrm{~cm}$ ), indicated by the vertical dashed line in Fig. 2D:

$$
\tau_{\mathrm{IU}}= \begin{cases}0.011 & x \leq 5.6(n=186 \text { colonies }) \\ 0.053 & x>5.6(n=188 \text { colonies }) .\end{cases}
$$

Because colony size, year, and site did not have statistically significant effects on the probability of recovery from infection, we pooled all years and sites to estimate that the probability of recovery, conditional on survival, is $\tau_{\mathrm{UI}}=0.38 \pm 0.07$ ( $n=48$ colonies).

\section{Growth}

Growth of uninfected colonies was modeled as a simple linear function of size $x$, based on the lack of relationship (in either mean or variance) between residuals and fitted values from the model, and the fact that addition of nonlinear (spline) terms explained only $3 \%$ of the residual variance. The fitted model for final size $y$ as a function of initial size $x$ is

$$
g_{j \mathrm{U}}(y \mid x)=\varphi(y \mid \mu=0.682+0.945 x, \sigma=0.53)
$$

$j \in\{\mathrm{U}, \mathrm{I}\}$ where $\varphi(\cdot \mid \mu, \sigma)$ is the density of a Gaussian distribution with mean $\mu$ and standard deviation $\sigma$. Not surprisingly, the fitted regression line says that small colonies tend to grow on average ( $\mu>x$ for $x$ small) while very large colonies tend to shrink $(\mu<x$ for $x>$ 12.4). A normal quantile-quantile plot of the residuals from the Eq. 6 model reveals a departure from normality in the upper tail, but as this involves $<5 \%$ of the data we retained the Gaussian distribution.

The changes in size of infected colonies (omitting the circled "outliers" in Fig. 3) can also be modeled as Gaussian, based on normal quantile-quantile plots and nonsignificant Shapiro-Wilk tests for nonnormality $(P$ 
A) Yucatán

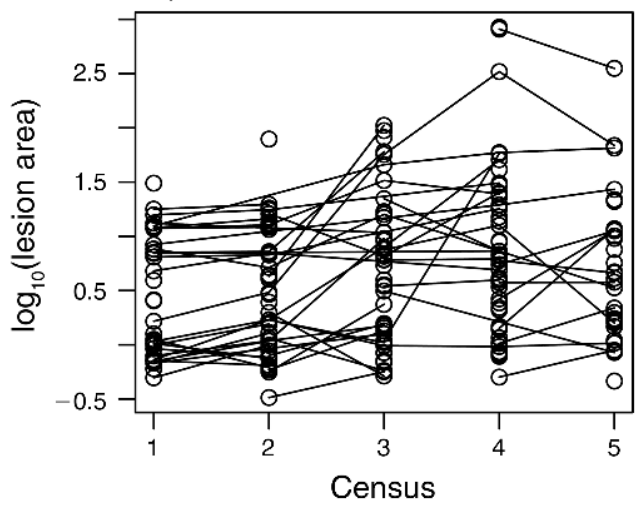

B) Florida Keys

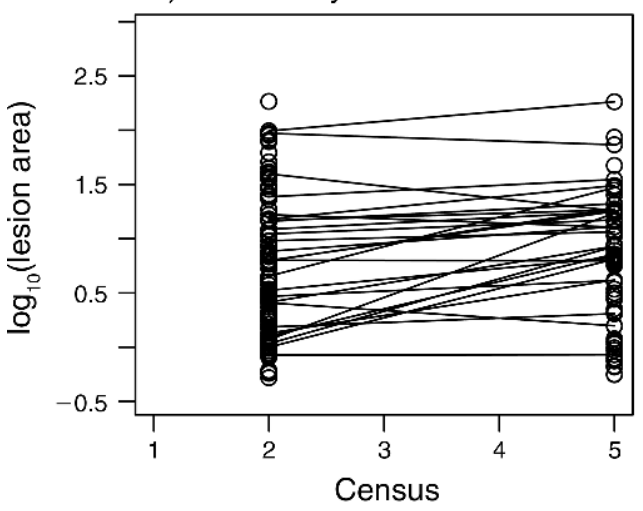

C) 1-year changes, Yucatán

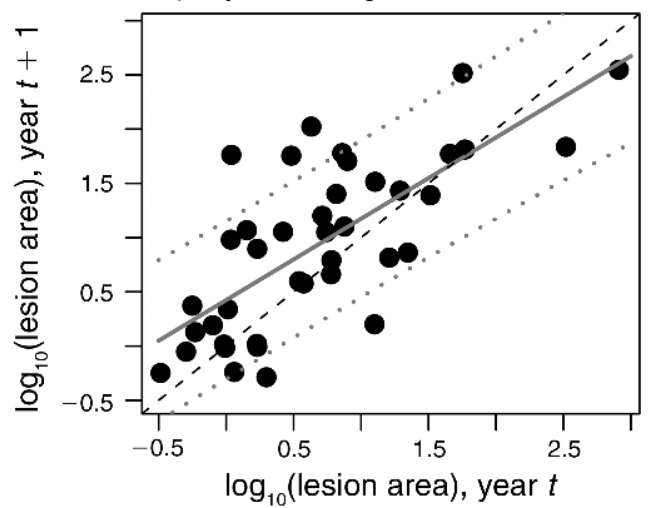

D) 3-year changes, Florida Keys

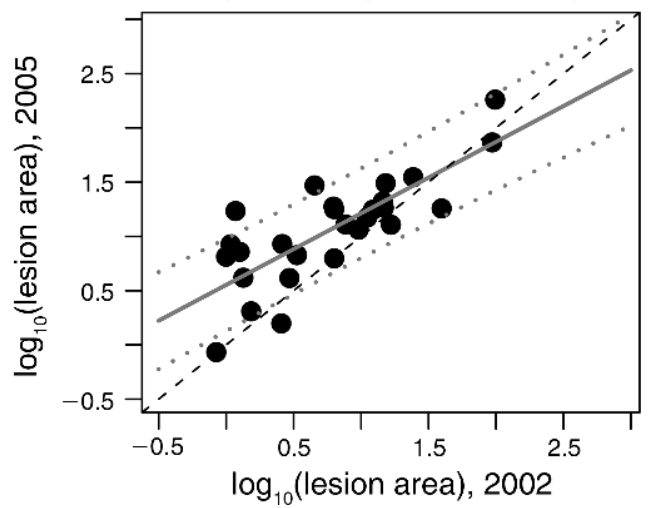

FIg. 4. Size dynamics of individual lesions. "Lesion size" is the total amount of tissue area classified as either actively growing lesion, colonized, or missing, for each lesion separately. (A) Lesion sizes at the five census intervals at sites along the Yucatán Peninsula. Census dates were: 1, January 2002; 2, July-August 2002; 3, July 2003; 4, July 2004; and 5, July-September 2005. Solid lines connect the same lesion measured at two different census times. (B) Lesion sizes at the five census intervals for sites in the Florida Keys. The format is as in panel (A). (C) All observed year-to-year changes in the total size of individual lesions (which may differ from the total lesion area on a colony, because colonies often have multiple lesions simultaneously). Because of the census intervals, all observed year-to-year changes were from Yucatán sites, census periods $2-5$. The dashed line is the 1:1 line. The solid line is a linear regression, with an $80 \%$ prediction interval shown by the surrounding dotted curves. (D) All observed year-to-year changes in the total size of individual lesions between the two censuses in the Florida Keys sites. The format is as in panel (C).

$>0.3$ for recovering and nonrecovering fans separately, and $P>0.1$ for the two groups pooled after centering each group to have mean $=0$ ). We also used a Gaussian model for the size change in the outliers (estimated mean $\pm \mathrm{SD}=-2.8 \pm 0.94 \mathrm{~cm})$ and used the fraction of outliers $(3 / 57 \approx 0.05)$ to estimate the probability of severe tissue loss. The growth kernels for infected colonies in the model are thus mixtures of normals:

$$
\begin{aligned}
g_{\mathrm{UI}}(y \mid x)= & 0.95 \varphi(y \mid \mu=x+0.27, \sigma=0.57) \\
& +0.05 \varphi(y \mid \mu=x-3.2, \sigma=0.52) \\
g_{\mathrm{II}}(y \mid x)= & 0.95 \varphi(y \mid \mu=x-0.33, \sigma=0.57) \\
& +0.05 \varphi(y \mid \mu=x-3.2, \sigma=0.52) .
\end{aligned}
$$

Mortality and infection risk of large colonies

The fitted models for mortality of infected and uninfected colonies (Fig. 2A, C) have the unrealistic property that the death rate drops to nearly zero for medium- to large-size colonies, because essentially no mortality of large colonies was observed in our demographic monitoring. Large colonies nonetheless eventually die, in particular during major storms when large fans would be most vulnerable to removal by strong waves (Birkeland 1974). No hurricanes or major storms struck our study sites during the period of demographic monitoring. For population modeling we therefore used data from Florida Keys transect surveys early in the epizootic (1997) to back-calculate the sizespecific mortality rate that would generate the observed size distribution (see Appendix B). This approach gives an average mortality rate rising sigmoidally from zero to $\sim 0.1$ colonies $/ \mathrm{yr}$ as colony height increases from $25 \mathrm{~cm}$ to $40 \mathrm{~cm}$. Because this is the only source of large-colony mortality in our model, it is one of the main determinants of colony longevity. 
The size dependence of disease prevalence that was observed during the epizootic (Fig. 5A) cannot be generated by the pattern of infection risk that was observed in our demographic monitoring data (Eq. 5), even if the overall infection risk is scaled up so that the model matches the average prevalence during the epizootic (Fig. 5B). We therefore used size-prevalence relationships in the early-outbreak transect survey data to estimate the size dependent infection risk, the diseaserelated mortality rate, and the probability of recovery from infection during the initial disease outbreak (see Appendix D). The estimated infection risk during the early-outbreak period is strongly size dependent, and the difference between the early-outbreak risk and the endemic-phase infection risk estimated from the demographic monitoring data (Fig. 5C) is statistically highly significant and substantial. When the size-dependent infection risk is used, the model generates a sizeprevalence relationship very similar to the observed pattern (Fig. 5D); this confirms that the fitting exercise was successful, but is not an independent test of the model.

\section{Population Model: Descriptive Properties}

\section{Size distributions}

The population model accurately predicted several demographic properties and temporal trends observed from field monitoring at sites in Florida and Mexico. One of the most basic predictions of the model is the steady-state number and size distributions of sea fan colonies. Comparing these with independent field observations is a measure of how well the model scales from colony-level to population-level properties. However, the comparison is not straightforward, because of the intermittent nature of hurricane-induced mortality, episodic recruitment, and so forth, and because our population samples reflect transient responses to the epizootic. We therefore asked whether the model is consistent with observed size distributions under plausible assumptions about recent population history.

The observed endemic-phase (2004) size distributions observed in the Yucatán and Florida Keys survey sites were very similar and were strongly right-skewed (Fig. $6 \mathrm{~A}, \mathrm{~B})$, presumably due to the loss of large colonies during the outbreak. These post-peak distributions were quite different from distribution in the Florida Keys prior to the epizootic peak (Fig. 6D, E), which was more normally distributed. The predicted steady-state size distribution from the population model parameterized using current endemic-phase (post-peak) data (Fig. 6C) is very similar to the observed post-peak (2004) size distributions (Fig. 6A, B). The endemic-phase transect survey data (shown in Fig. 6A, B) were not used in constructing or parameterizing the demographic model. Therefore, this comparison (of model predictions against independent field observations) indicates that the model described natural population dynamics and properties fairly accurately. However, the model's damping ratio (the ratio between the second-largest and dominant eigenvalues) is 0.84 , which implies that 5 years under current conditions would reduce deviations from the steady state by $\sim 60 \%$.

We also compared model predictions to observed population changes during different stages of the epizootic. We assumed that the size distribution of uninfected colonies at the Keys transect sites (Molasses, Alligator, and Tennessee reefs) where mortality from the epizootic was still low in 1997 (Kim and Harvell 2002), was representative of the general pre-epizootic size distribution. We used the model to predict the preepizootic size distribution (Fig. 6F) by making two changes in the model: the risk of infection was set to zero and the recruitment-rate parameter $b$ was decreased to reflect trends in recruitment during this phase (see Appendix C). The model predicted slightly more large colonies than we observed in the early-outbreak Florida Keys surveys (Fig. 6E). However, when the model population is exposed to disease for three years (using the estimated early-outbreak disease-process parameters described in Appendix D), the predicted size distribution of uninfected colonies (Fig. 6F) shows a shift towards smaller colonies. This predicted distribution is more comparable to our estimated pre-epizootic (Fig. 6D) and early-epizootic (Fig. 6E) size distributions.

\section{Population Model: Projections}

\section{Local outbreak severity and recruitment}

Because infected colonies cease to reproduce and tend to become smaller (and therefore less fecund upon recovery), there is a close link between outbreak severity and recruitment rate. We simulated epizootics of varying intensity in the model by multiplying the size-dependent risk of infection and the chance of recovery by factors ranging from 0.01 to 100 in the early-outbreak diseaseprocess parameters (as described in Appendix D). We began the simulations with a disease-free population at steady state, ran the epizootic for four years, and computed the final disease prevalence and total recruitment (Eq. 4). Fig. 7A shows the relationship between disease prevalence and total recruitment rate in these simulations. Even in situations where half or more of the population is uninfected, recruitment rate is greatly reduced because the population size-structure has shifted toward a high frequency of smaller, less fecund colonies. This pattern of reduced recruitment matches the observed relationship between local disease prevalence and local recruit density in our Florida Keys permanent transects (Fig. 7B).

\section{Elasticity and perturbation analyses}

Despite the strong predicted and observed effects of the epizootic on reproduction, elasticity analysis (Appendix E) indicates that the highest contribution to population growth comes from survival and growth of established colonies, rather than recruitment (Appendix E: Fig. E1, Table E1) at all stages of the epizootic. By the end of our demographic monitoring, the disease was 
A) Florida Keys, 1997-1998

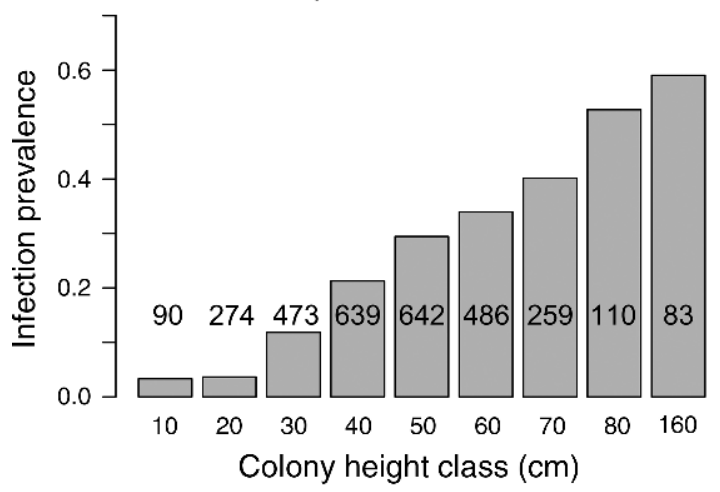

B) Model with constant infection risk (endemic phase)

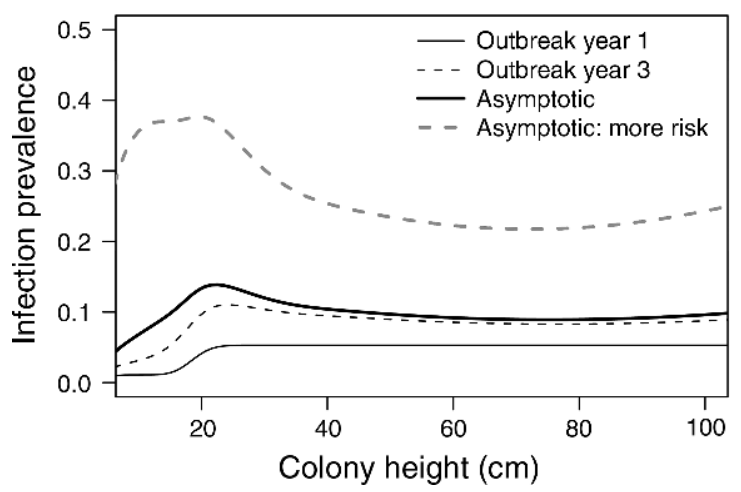

C) Inferred early-outbreak infection risk

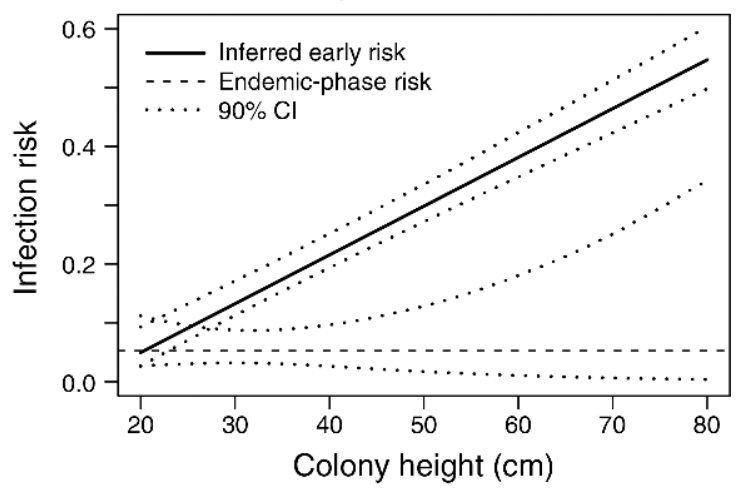

D) Model with size-dependent infection risk (early outbreak)

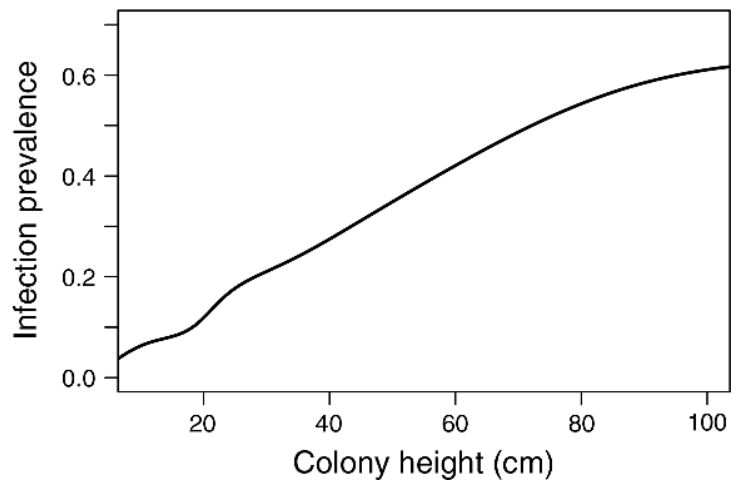

FIG. 5. Size-prevalence relationships and size-dependent infection risk. (A) Disease prevalence as a function of colony height class, pooling data from all surveys in 1997 and 1998 of the six permanent transect sites in the Florida Keys (USA) described by Kim and Harvell (2004). The number of colonies in each height class is given on the histogram bars. Height class 10 runs from 0 through $10 \mathrm{~cm}$, height class 20 from 11 through $20 \mathrm{~cm}$, and so on, with the last class including all colonies $>80 \mathrm{~cm}$ in height. (B) Size-prevalence relationships predicted by the population model, using the size-dependent infection risk estimated from the Yucatán Peninsula demographic monitoring data (Eq. 5). Black curves show disease prevalence one and three years after the start of an outbreak, and the asymptotic size-prevalence relationship when the model has converged to steady state. The dashed gray curve shows the asymptotic size-prevalence relationship if the infection risk is increased and the recovery rate decreased to match the observed overall prevalence of $\sim 30 \%$ at the epizootic peak. (C) The size-dependent infection risk inferred from the earlyoutbreak size-prevalence relationships, as described in Appendix D (solid curve), compared with the infection risk estimated from Yucatán demographic monitoring data, Eq. 5. Dotted lines are pointwise two-sided $90 \%$ confidence bands on the infection-risk estimates, computed by drawing 10000 parameter samples according to the variance-covariance matrix of fitted model parameters and computing pointwise quantiles of the resulting infection-risk curves. (D) The size-prevalence relationships predicted by the population model, using the inferred early-outbreak size-dependent infection risk (solid curve in panel C).

endemic at low levels, and population growth was most sensitive to transitions within the "uninfected" category (Table E1). This was also true for parameters representing the outbreak peak, but for a different reason: the high mortality of infected colonies makes infectedinfected transitions rare and therefore they have low elasticity.

We also computed how perturbations of some of the underlying rate functions that go into the projection kernel affect the population growth rate $\lambda$ (Appendix $E$ : Fig. E2). In the endemic phase, population growth is affected most strongly by changes in the mortality of uninfected colonies (Fig. E2C) but was also influenced by changes in uninfected colony growth rate and fecundity. Colony growth is beneficial for population growth insofar as larger colonies have higher per capita fecundity, but larger colonies also experience higher hurricane-related mortality, so the gains from increased growth rate are smaller than those from decreased mortality. Changes in fecundity also have a relatively small impact until fecundity falls nearly to zero. Under pre-epizootic conditions (Fig. E2A), increased colony growth rate is actually slightly detrimental to population growth rate in the model, presumably because fecundity is lower overall so the gain in fecundity from increased mean colony size is smaller. During the outbreak peak (Fig. E2B) increased colony growth would be detrimental due to the higher infection risk of larger colonies and the mortality rate of infected fans naturally becomes more important. 


\section{A) Florida Keys 2004, uninfected}

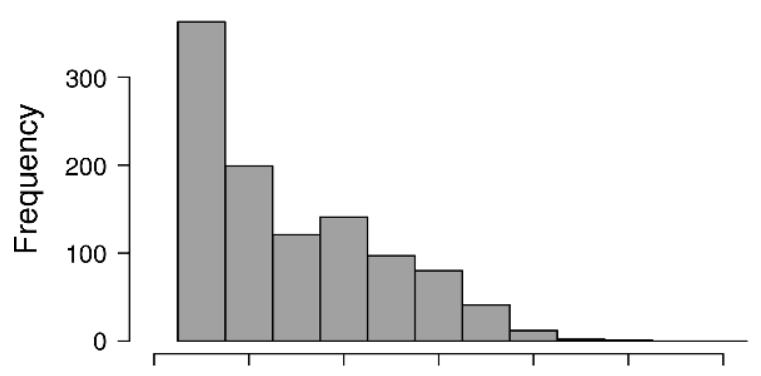

B) Akumal 2004, uninfected

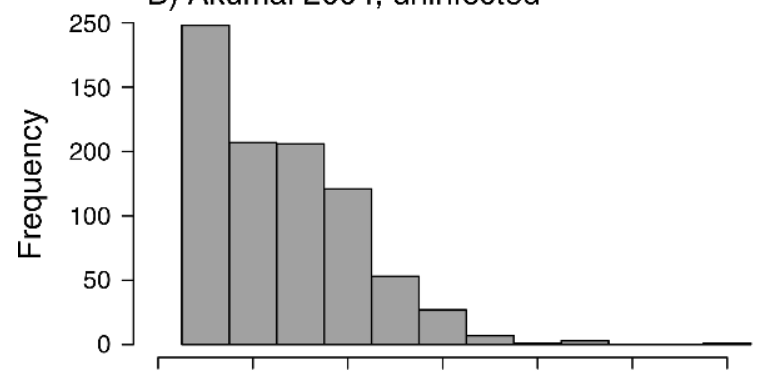

C) Model: endemic (post-peak) phase

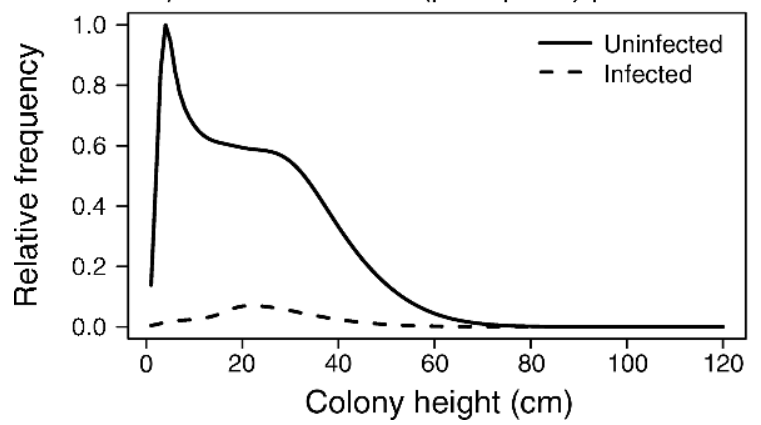

D) Upper Keys 1997, all

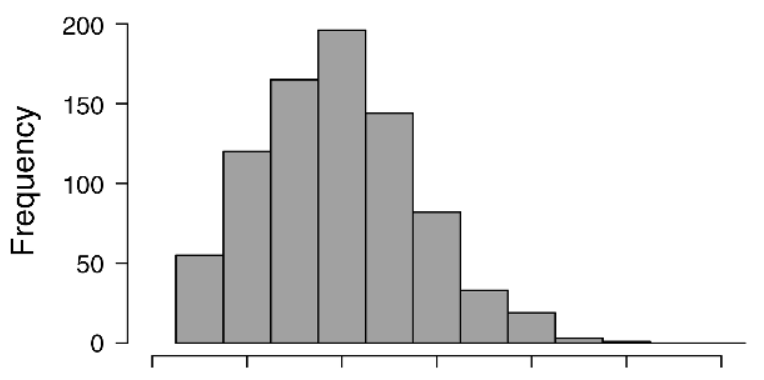

E) Florida Keys 1997, uninfected

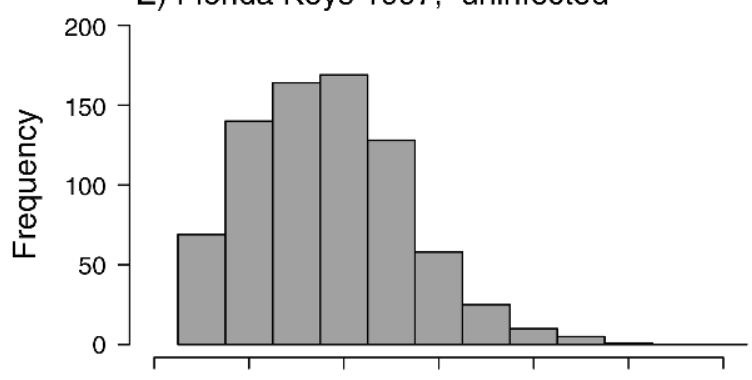

F) Model: pre- and peak-epizootic

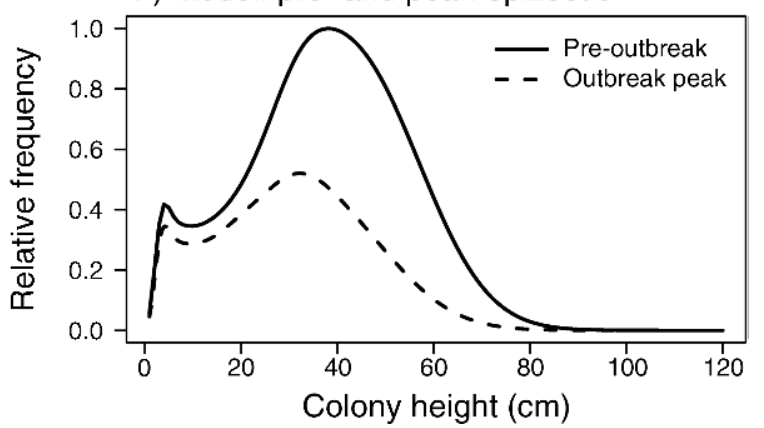

FIG. 6. Model predictions compared with the size distributions of uninfected sea fan colonies in transect surveys. Panels A, B, and $\mathrm{C}$ all concern the endemic phase, for which we can compare model predictions with completely independent size-distribution data collected from nearby sites at exactly the same time. Panels D, E, and F concern the early-outbreak phase, for which some model parameters were estimated based on the size distribution data. (A, B) Height distribution of apparently uninfected colonies in all 2004 Florida Keys transect surveys, and all transects surveyed near Akumal (Yucatán Peninsula, Mexico) in 2004, omitting colonies $5 \mathrm{~cm}$ in height or smaller. The Yucatán data were taken at locations different from, but near to, the sites used for demographic monitoring of tagged colonies. (C) Model predictions for the steady-state height distributions of uninfected (solid) and infected (dashed) colonies under current (post-epizootic peak) conditions. (D) Height distribution of all living colonies in three Upper Florida Keys transect survey sites in 1997, where mortality from the epizootic was still low. (E) Height distribution of all colonies showing no signs of infection in all Florida Keys transect survey sites in 1997. (F) Model predictions of pre- and earlyepizootic height distributions. The solid curve is the predicted steady state size distribution prior to disease outbreak. The dashed curve shows the size distribution of uninfected colonies, starting from the pre-outbreak prediction and imposing the disease for three years (i.e., 1995, 1996, 1997) using the estimated early-outbreak disease process parameters (as described in Appendix D).

\section{Evolution of resistance: what ended the epizootic?}

The prevalence of sea fan aspergillosis was detected at peak levels between 1994 and 1997 and then waned (Kim and Harvell 2004). Possible explanations for the decline include changes in environmental conditions (e.g., temperature or pollutants), reduced pathogen input or virulence, and increased host resistance (Kim and Harvell 2004). We used the population model to explore the plausibility of the host-resistance hypothesis, specifically whether host evolution could proceed quickly enough to explain the observed decrease in prevalence from $\sim 30 \%$ in 1997 to $<10 \%$ by 2003 . Infection risk was initially strongly positively size dependent, but the observed degree of size dependence following the epizootic was negligible (Fig. 5C). The size-specific infection risk and disease-induced mortality caused a shift in the population size distribution in all sites towards smaller colonies and a lower total tissue area (Fig. 6, Kim and Harvell 2004). One explanation 

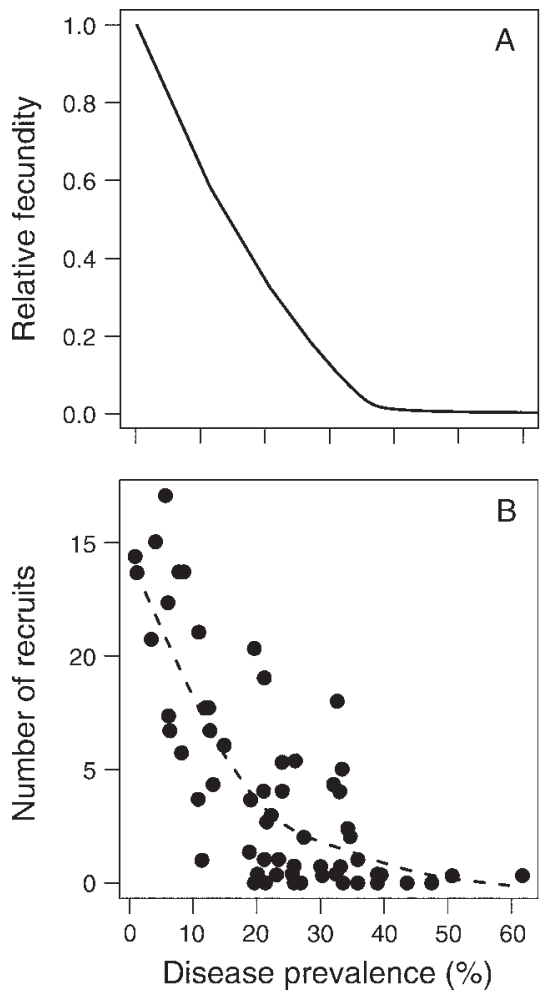

FIG. 7. Modeling disease impacts on recruitment. (A) Predicted relationship between disease prevalence and total fecundity of a local population. "Relative fecundity" is the total annual production of recruits by the population as a function of disease prevalence, relative to the value when the disease is absent. (B) Observed relationship between local disease prevalence and the number of sea fan recruits (defined as colonies $<10 \mathrm{~cm}$ in height) in $25 \times 2 \mathrm{~m}$ transect survey plots in the Florida Keys (the figure is redrawn from Fig. 5 of Kim and Harvell [2004]).

concordant with these patterns is that large susceptible colonies were culled from the population, and the remaining colonies were largely resistant to infection.

We simulated this scenario in the model by applying the estimated early-outbreak size-dependent infection risk and disease parameters to a population that initially included a proportion of colonies that were completely resistant to the disease and produced offspring that were also completely resistant (Fig. 8). Once the outbreak starts, the model predicts a steady increase in the fraction of resistant colonies, so that within a few years disease prevalence starts to decline. Although the simulated rise and fall in disease prevalence are slightly smaller and slower than the observed trend, these simulations suggest that rapid evolution in host resistance due to differential mortality could play a role in the decline of the epizootic. This scenario for host evolution also explains the observed change in the size dependence of infection risk as the epizootic progresses (Fig. 9B). Because larger colonies are at high risk of infection and, when infected, experience high disease- related mortality, colonies that are both large and susceptible are quickly removed from the population. The average infection risk of the remaining large fans decreases, resulting in an average infection risk with only weak size dependence among larger colonies $(20 \mathrm{~cm}$ or taller). Thus, host evolution could also explain how the degree of the size dependence in infection risk changed as the epizootic progressed (Fig. 5C).

\section{Population turnover and recovery from a disease outbreak}

An important goal was to determine the duration of disease impacts on sea fan populations. Because disease is a major cause of wildlife population fluctuations and decline, resource managers need to be able to distinguish mild from severe outbreaks so that management interventions match the threat to the population and the duration of the impacts. In most cases, during an outbreak, particularly in the early phases, managers will
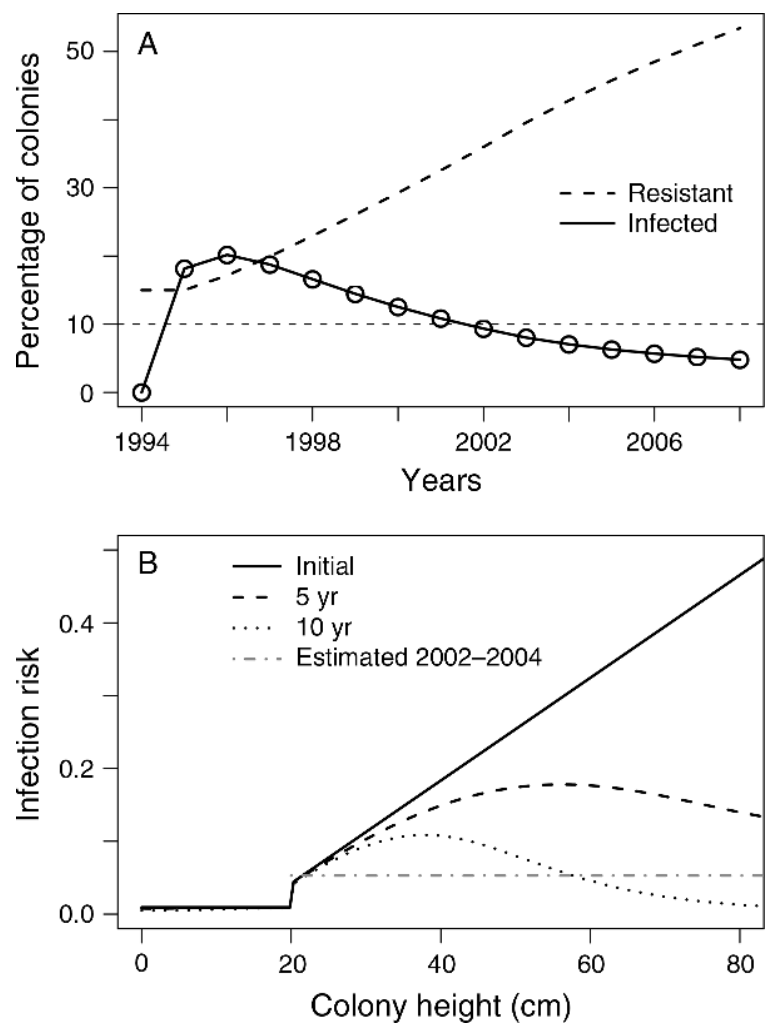

FIG. 8. Modeling host evolution and the fall of the epizootic. (A) Simulation of resistance evolution, assuming an initial population in which $15 \%$ of colonies are completely disease-resistant. The estimated early-outbreak disease parameters were modified by increasing the infection risk of susceptible fans by $15 \%$ to compensate for the resistant colonies. (B) Changes in the size dependence of infection risk as the epizootic continues. The curves show the average sizedependent infection risk of uninfected colonies in the population prior to the outbreak (solid line) and 5 years (dashed line) and 10 years (dotted line) following the start of the outbreak. The dash-dot line is the endemic-phase infection risk estimated from the Yucatán Peninsula demographic monitoring data. 
only have the resources to quantify basic disease attributes, e.g., prevalence and perhaps incidence. An ability to relate simple measures of disease severity to the longer-term consequences for the host population would be an invaluable management tool.

Because sea fan reproduction is strongly size dependent and the epizootic's primary impact was on population size structure rather than total population density, one important measure of population recovery is return to the pre-epizootic size distribution. The rate at which the size distribution returns following a perturbation in the population model is approximated by the damping ratio, the ratio between the magnitudes of the subdominant and dominant eigenvalues. This is approximately 0.86 , implying $80 \%$ return within 10 years. The rapid recovery reflects the facts that colony life spans are on the order of decades (Fig. 9A) and that colonies may grow within a few decades into the size ranges that were dominant prior to the outbreak (Fig. 9B). As a result, the population model shows substantial return to pre-epizootic size structure within 10 years, and within 25 years the size structure is nearly identical to the steady-state size structure.

Another measure of recovery is return to the preepizootic amount of healthy tissue. We used the population model to predict the time required for recovery in this sense from epizootics whose damage to the population ranged from mild to extreme. The amount of damage from the epizootic was measured by the percentage of healthy tissue area lost from the population due to infection, and "recovery" was defined as a return to $95 \%$ of the pre-outbreak total healthytissue area. We varied several aspects of the epizootic including duration $(3,10$, or 20 years) and severity (infection risk, recovery probability and disease-related mortality rate) to estimate their influence on the immediate and longer-term effects on sea fan demography.

The predicted duration of the impacts could also be sensitive to several factors that would be influenced by the spatial scale of the outbreak. To address this, we predicted recovery time using two scenarios: (1) a "local population" outbreak (in which recruits are supplied at a constant rate from a global population unaffected by the epizootic) and (2) a "global population" outbreak (where few recruits came from outside populations unaffected by the epizootic). These two populationconnectivity scenarios relate to the scale of the outbreak. In the local model, the outbreak is local and the fecundity of outside source populations is unaffected, and thus recruitment remains constant. In the global model, the outbreak is assumed to be regional, reducing fecundity at all potential source populations, thereby greatly reducing recruitment.

Our model predicts that the time to recovery of total tissue area is largely determined by the total loss of healthy tissue due to the epizootic (Fig. 9C), rather than the specific factors that affect the amount of tissue loss (e.g., whether high tissue loss resulted from high infection risk vs. long duration of the epizootic). This was especially true for the global-outbreak model (Fig. 9D; note the difference in the scale of the $y$ axis compared to Fig. 9C) when tissue loss exceeds $80 \%$ (which is much greater loss than occurred during the actual epizootic). Because the population's total fecundity in the global-outbreak model is strongly negatively related to disease prevalence, recovery could take several centuries when the epizootic is especially severe.

However, when the amount of tissue loss is smaller, the degree of demographic connectivity had a much smaller affect on recovery time; for example, at $50 \%$ tissue loss there is only about a two-fold difference in recovery times between the global- and local- outbreak models. The relative unimportance of reproduction before and after the epizootic results from the longevity of established colonies (Fig. 9A), which implies that population decline would be gradual even if reproduction were completely eliminated. Recruitment is obviously essential for the persistence of the population over longer time scales (i.e., centuries), but its impact is the difference between slow decline and very slow population growth. Even in the absence of disease, the population model estimates that sea fan population growth rate $(\lambda)$ is only 1.01 . Therefore, recovery time can be relatively long, ranging from decades to centuries, depending on several aspects of the population and outbreak. This also means there is great uncertainty about recovery time; increasing $\lambda$ during the recovery phase to just 1.02 reduced recovery time by nearly half (Fig. 9E). Given this uncertainty and the many factors that contribute to population recovery, caution is clearly warranted when interpreting the model's predictions about recovery time.

\section{DiscusSION}

Our results highlight the complexity of host-pathogen interactions, particularly the interplay between the effects of epizootics on host demography and the evolution of resistance. The initial strong size dependence of infection risk greatly increased the impacts of the disease by shutting down reproduction in many of the largest and normally most fecund individuals and by skewing the population size structure towards dominance by smaller, less fecund (or nonreproductive) colonies. But this aspect of the epizootic could have facilitated the rapid selection for resistance among larger colonies, and the differential survival of resistant fans may have been a cause of the observed gradual decline of prevalence.

We initially asked why sea fans were resilient to a highly virulent pathogen, in part because understanding host resilience would be valuable for coral conservation. Unfortunately, our findings suggest that resilience may have been due in part to good luck, i.e., the preexistence of genotypes that resist or survive infection, even though the populations have no known prior history of 

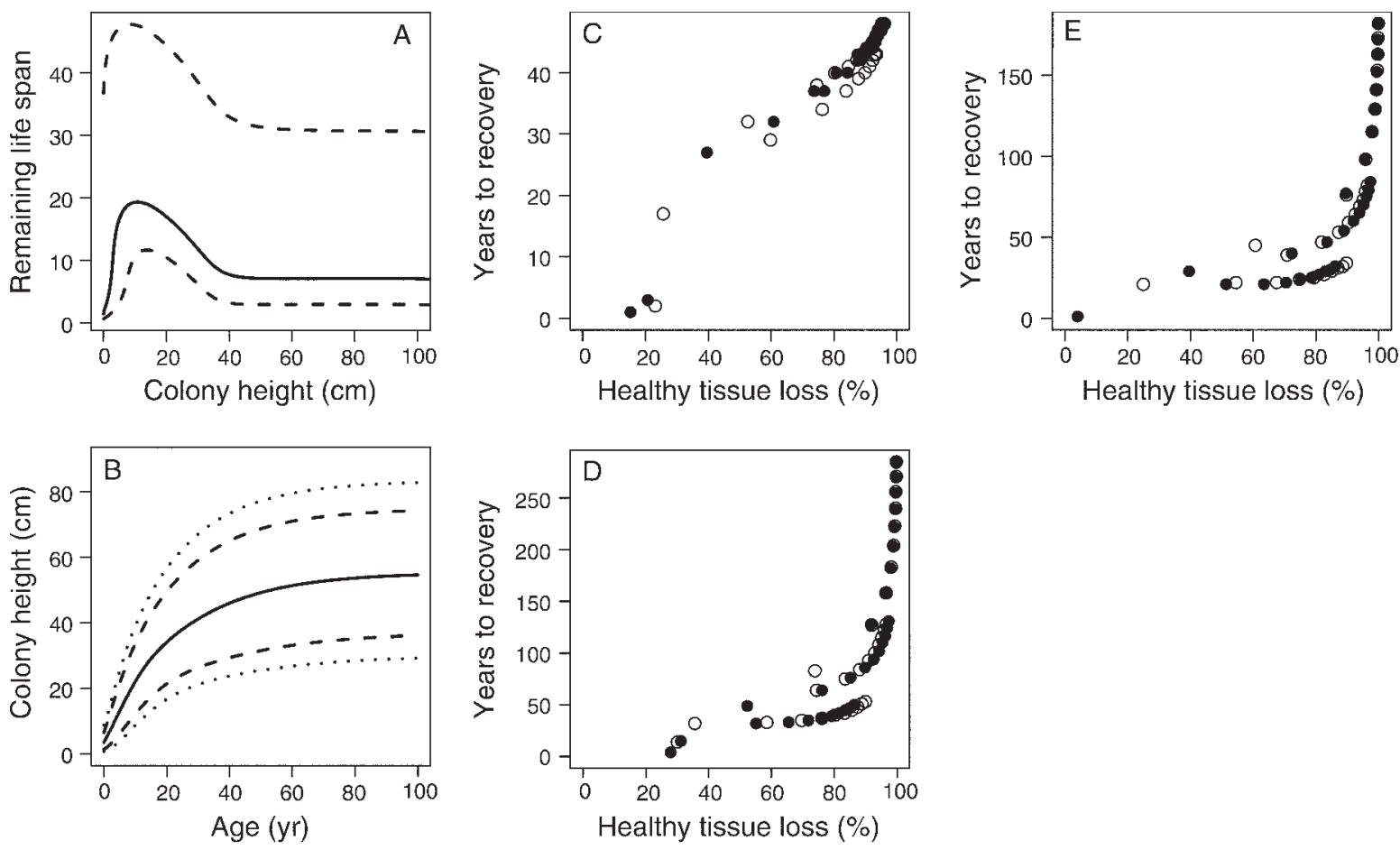

FIG. 9. Population turnover and recovery from disease outbreak. (A) Remaining life span as a function of current colony size (solid curve, median; dashed curves, 25th and 95th percentiles). (B) Colony size as a function of age (solid curve, median; dashed curves, 5th and 95th percentiles; dotted curves, 1st and 99th percentiles) when the standard deviation of annual growth increments was reduced by $20 \%$. (C-E) Time required for the total surface area of all colonies in a local population to recover from an epizootic to $95 \%$ of the pre-epizootic level based on (C) a "local population" model (in which recruits are supplied at a constant rate from a global population unaffected by the epizootic) and $(\mathrm{D}, \mathrm{E})$ a "global population" model in which the entire population is affected by the epizootic. Populations were initialized at the model's steady state with zero disease risk and subjected to epizootics (using the estimated early outbreak disease parameters) that varied in duration (3, 10, or 20 years) and severity. Open circles show results when severity was varied by increasing infection risk and decreasing recovery probability by a common factor, leaving the disease-related mortality rate constant; solid circles show results when the disease-related mortality rate was increased by the same factor as infection risk. The survival kernel was increased by $1 \%$ in panel (E) relative to that in panel (D) $(\lambda$ was 1.01 and 1.02 , respectively).

exposure to this pathogen. Current populations, dominated by these individuals and their descendants, have low infection risk and high odds of recovery. Lacking pre-outbreak samples, we cannot obtain direct genetic evidence for evolution of host resistance. However, there is increasing evidence in other species of increased host resistance following natural or experimental epizootics (Fenner and Ratcliffe 1965, Ibrahim and Barrett 1991, Duffy and Sivars-Becker 2007, Duncan and Little 2007, Zbinden et al. 2008).

Every measured aspect of the etiology of sea fan aspergillosis changed over time. Many of the observed individual- and population-level changes in the impacts of the fungal pathogen are theoretically predicted, but rarely observed in natural populations, particularly in marine or colonial species. Our study illustrates the value of basic demographic information in understanding the dynamics of fundamental ecological processes, but also highlights the limitation of one-time demographic "snap shots." Given the changes in host demography and disease etiology during our study, short-term observations during different stages of the epizootic would have led to various impressions about severity of the impacts to the host population and the rate or probability of recovery.

Previous research suggests that environmental factors, including nutrient concentration, could influence the rate of within- and among-colony disease spread (Bruno et al. 2003, Voss and Richardson 2006). However, the lack of basic information about host demography made it difficult to put this work into a demographic and temporally meaningful context. For example, it is plausible that doubling infection rate might have very little effect on the realized pathogen impacts on characteristics such as host population growth rate or size structure. The epizootic substantially decreased the total surface area of most of our monitored populations but had surprisingly little effect on population density, despite the strong recruitment bottleneck that populations experienced for several years.

Assessing the sensitivity of host demography to an epizootic and the potential for evolved resistance requires quantification of vital rates and the impacts of infection on those rates, throughout the course of an 
outbreak. Our present example provides the most comprehensive picture of the demographic dynamics during a coral disease outbreak in a resilient species. In the seafan Aspergillus outbreak the key components of host resilience appear to be large population size, a weedy life history (relative to other corals) and the presence of resistant individuals in the initial population. With both a changing climate and increased nutrient stress expected to facilitate disease outbreaks in alreadystressed coral communities, realistic modeling tools are required for projecting impacts and forecasting outcomes. Understanding the demographic impacts of disease will also allow ecologists to place these impacts in the context of other forces regulating populations, such as predation, competition, and abiotic disturbances.

\section{ACKNOWLEDGMENTS}

A large number of colleagues, students, and technicians helped collect the demographic data and analyze the sea fan images, including Lauren Bethune, Will Eaton, Peter Edmunds, Johanna Kertesz, Jacqueline Padilla-Gamino, Jason Landrum, Sarah Lee, Mary O'Connor, Laura Petes, Elizabeth Selig, Chris Shields, Shauna Slingsby, Sam Taylor, and Jessica Wall. We appreciate comments on the manuscript by Courtney Couch, Morgan Mouchka, Jason Andras, David Baker, Elizabeth MacLeod, and the anonymous referees. This research was funded in part by an EID grant from the National Science Foundation (OCE-0326705), the NOAA National Undersea Research Center, the Coral Disease Working Group of the GEF-Coral Reef Targeted Research Program, Cornell University, and the University of North Carolina at Chapel Hill. We are grateful to the NOAA NURC crew, particularly Mike Burns, for their assistance in surveying the Florida Keys sites and the Akumal Dive Shop and the Centro Ecológico Akumal for providing logistical support in Mexico.

\section{Literature Cited}

Alker, A. P., K. Kim, D. H. Dube, and C. D. Harvell. 2004. Localized induction of a generalized response against multiple biotic agents in Caribbean sea fans. Coral Reefs 23:397-405.

Aronson, R. B., J. F. Bruno, W. F. Precht, P. W. Glynn, C. D. Harvell, L. Kaufman, C. S. Rogers, E. A. Shinn, and J. F. Valentine. 2003. Causes of coral reef degradation. Science 302:1502.

Baker, D. M., S. E. MacAvoy, and K. Kim. 2007. The relationship between water quality, $\delta 15 \mathrm{~N}$, and aspergillosis of Caribbean sea fan corals. Marine Ecology Progress Series 343:123-130.

Birkeland, C. 1974. The effects of wave action on the population dynamics of Gorgonia ventalina Linnaeus. Studies in Tropical Oceanography 12:115-126.

Bruno, J. F., L. E. Petes, C. D. Harvell, and A. Hettinger. 2003. Nutrient enrichment can increase the severity of coral diseases. Ecology Letters 6:1056-1061.

Bruno, J. F., E. R. Selig, K. S. Casey, C. A. Page, B. L. Willis, C. D. Harvell, H. Sweatman, and A. M. Melendy. 2007. Thermal stress and coral cover as drivers of coral disease outbreaks. PLoS Biology 5:3124.

Caswell, H. 2001. Matrix population models. Sinauer Associates, Sunderland, Massachusetts, USA.

Duffy, M. A., and L. Sivars-Becker. 2007. Rapid evolution and ecological host-parasite dynamics. Ecology Letters 10:44-53.

Duncan, A. B., and T. J. Little. 2007. Parasitic-driven genetic change in a natural population of Daphnia. Evolution 61: 796-803.
Easterling, M. R., S. P. Ellner, and P. M. Dixon. 2000. Sizespecific sensitivity: applying a new structured population model. Ecology 81:694-708.

Ellner, S. P., L. E. Jones, L. D. Mydlarz, and C. D. Harvell. 2007. Within-host disease ecology in the sea fan Gorgonia ventalina: Modeling the spatial immunodynamics of a coralpathogen interaction. American Naturalist 170:E143-E161.

Ellner, S. P., and M. Rees. 2006. Integral projection models for species with complex demography. American Naturalist 167: 410-428.

Falkowski, P., Z. Dubinsky, L. Muscatine, and J. Porter. 1984. Light and the bioenergetics of a symbiotic coral. BioScience 34:705-709.

Fenner, F., and F. N. Ratcliffe. 1965. Myxomatosis. Cambridge University Press, London, UK.

Ford, S. E., and A. J. Figueras. 1988. Effects of sublethal infection by the parasite Haplosporidium nelsoni (MSX) on gametogenesis, spawning, and sex ratios of oysters in Delaware Bay, USA. Diseases of Aquatic Organisms 4:121133.

Harvell, C., and W. Fenical. 1989. Chemical and structural defenses of Caribbean gorgonians (Pseudopterogorgia spp.). II. Intra-colony localization of defense. Limnology and Oceanography 34:382-389.

Hughes, R. N. 1983. Evolutionary ecology of colonial-reef organisms, with particular reference to corals. Biological Journal of the Linnean Society 20:39-58.

Hughes, T. P., and J. H. Connell. 1987. Population dynamics based on size or age? A reef-coral analysis. American Naturalist 129:818-829.

Ibrahim, K. M., and J. A. Barrett. 1991. Evolution of mildew resistance in a hybrid bulk population of barley. Heredity 67 : 247-256.

Jolles, A. E., P. Sullivan, A. P. Alker, and C. D. Harvell. 2002. Disease transmission of aspergillosis in sea fans: inferring process from spatial pattern. Ecology 83:2373-2378.

Kim, K., and C. D. Harvell. 2002. Aspergillosis of sea fan corals: disease dynamics in the Florida Keys. Pages 813-824 in J. W. Porter and K. G. Porter, editors. The Everglades, Florida Bay, and coral reefs of the Florida Keys: an ecosystem sourcebook. CRC Press, Boca Raton, Florida, USA.

Kim, K., and C. D. Harvell. 2004. The rise and fall of a six-year coral-fungal epizootic. American Naturalist 164:S52-S63.

Leverette, C. L., M. Warren, M. A. Smith, and G. W. Smith. 2008. Determination of carotenoid as the purple pigment in Gorgonia ventalina sclerites using Raman microscopy. Spectrochimica Acta Part A: Molecular and Biomolecular Spectroscopy 69:1058-1061.

Linares, C., R. Coma, D. Diaz, M. Zabala, B. Hereu, and L. Dantart. 2005. Immediate and delayed effects of a mass mortality event on gorgonian population dynamics and benthic community structure in the NW Mediterranean Sea. Marine Ecology Progress Series 305:127-137.

Mullen, K. M., C. Harvell, A. Alker, D. Dube, E. Jordan, J. R. Ward, and L. Petes. 2006. Host range and resistance to aspergillosis in three sea fan species from the Yucatán. Marine Biology 149:1355-1364.

Mydlarz, L. D., and C. D. Harvell. 2007. Peroxidase activity and inducibility in the sea fan coral exposed to a fungal pathogen. Comparative Biochemistry and Physiology_-Part A: Molecular and Integrative Physiology 146:54-62.

Mydlarz, L. D., S. F. Holthouse, E. C. Peters, and C. D. Harvell. 2008. Cellular responses in sea fan corals: granular amoebocytes react to pathogen and climate stressors. PLoS ONE 3(3):e1811.

Nagelkerken, I., K. Buchan, G. W. Smith, K. Bonair, P. Bush, J. Garzón-Ferreira, L. Botero, P. Gayle, C. Heberer, C. Petrovic, L. Pors, and P. Yoshioka. 1997. Widespread disease in Caribbean sea fans. I. Spreading and general characteristics. Pages 679-682 in H. A. Lessios and I. G. Macintyre, 
editors. Proceeding of the Eighth International Coral Reef Symposium. Smithsonian Tropical Research Institute, Panama.

Petes, L. E., C. D. Harvell, E. C. Peters, M. A. H. Webb, and K. M. Mullen. 2003. Pathogens compromise reproduction and induce melanization in Caribbean sea fans. Marine Ecology Progress Series 264:167-171.

Pinheiro, J., D. Bates, S. DebRoy, D. Sarkar, and the R Core Team. 2007. nlme: linear and nonlinear mixed effects models. $\mathrm{R}$ package version 3.1-83. R Foundation for Statistical Computing, Vienna, Austria.

Powell, E. N., J. M. Klinck, and E. E. Hoffman. 1996. Modeling diseased oyster populations. 2. Triggering mechanisms for Perkinsus marinus epizootics. Journal of Shellfish Research 15:141-165.

R Development Core Team. 2007. R: a language and environment for statistical computing, version 2.3. R Foundation for Statistical Computing, Vienna, Austria.

Rypien, K. L. 2008. African dust is an unlikely source of Aspergillus sydowii, the causative agent of sea fan disease. Marine Ecology Progress Series 367:125-131.

Rypien, K. L., J. P. Andras, and C. D. Harvell. 2008. Globally panmictic population structure in the opportunistic fungal pathogen Aspergillus sydowii. Molecular Ecology 17:40684078.

Rypien, K. L., and D. M. Baker. 2009. Isotopic labeling and antifungal resistance as tracers of gut passage of the sea fan pathogen, Aspergillus sydowii. Diseases of Aquatic Organisms $86: 1-7$.
Seber, G. A. F., and C. J. Wild. 1989. Nonlinear regression. John Wiley and Sons, New York, New York, USA.

Smith, G. W., L. D. Ives, I. A. Nagelkerken, and K. B. Ritchie. 1996. Caribbean sea-fan mortalities. Nature 383:487.

Toledo-Hernandez, C., A. Zuluaga-Montero, A. Bones-Gonzalez, J. A. Rodriguez, A. M. Sabat, and P. Bayman. 2008. Fungi in healthy and diseased sea fans (Gorgonia ventalina): Is Aspergillus sydowii always the pathogen? Coral Reefs 27: 707-714.

Voss, J. D., and L. L. Richardson. 2006. Nutrient enrichment enhances black band disease progression in corals. Coral Reefs 25:569-576.

Wahle, C. M. 1980. Detection, pursuit, and overgrowth of tropical gorgonians by milleporid hydrocorals: Perseus and Medusa revisited. Science 209:689-690.

Ward, J. R., K. L. Rypien, J. F. Bruno, C. D. Harvell, E. Jordán-Dahlgren, K. M. Mullen, R. E. Rodríguez-Martínez, J. A Sánchez, and G. Smith. 2006. Coral diversity and disease in Mexico. Diseases of Aquatic Organisms 69:23-31.

Weil, E., A. Croquir, and I. Urreiztieta. 2009. Yellow band disease compromises the reproductive output of the Caribbean reef-building coral Montastraea faveolata (Anthozoa, Scleractinia). Diseases of Aquatic Organisms 87:45-55.

Wood, S. 2008. The mgcv package: GAMs with GCV smoothness estimation and GAMMs by REML/PQL. R Foundation for Statistical Computing, Vienna, Austria.

Zbinden, M., C. R. Haag, and D. Ebert. 2008. Experimental evolution of field populations of Daphnia magna in response to parasite treatment. Journal of Evolutionary Biology 21: $1068-1078$.

\section{APPENDIX A}

Estimating height-area relationships (Ecological Archives M081-006-A1).

\section{APPENDIX B}

Estimating storm-related mortality of large colonies (Ecological Archives M081-006-A2).

\section{APPENDIX C}

Modeling trends in recruitment since the start of the epizootic (Ecological Archives M081-006-A3).

\section{APPENDIX D}

Estimating the size-dependence of infection risk during the early epizootic (Ecological Archives M081-006-A4).

\section{APPENDIX E}

Elasticity and perturbation analyses (Ecological Archives M081-006-A5). 